\title{
Developing a New e-Exam Platform to Enhance the University Academic Examinations: the Case of Lebanese French University
}

\author{
Mazin S. Al-Hakeem \\ Department of IT, Lebanese French University (LFU), Erbil, Kurdistan-Iraq \\ E-mail: dr.mazin@lfu.edu.krd \\ Mohammad Salim Abdulrahman \\ Department of IT, Lebanese French University (LFU), Erbil, Kurdistan-Iraq \\ E-mail:mhmaditp@lfu.edu.krd
}

\begin{abstract}
Although the philosophy of education of many universities began shifted gradually towards using computers and information and communication technologies to establish effective education environment, the traditional style of examinations (that suffering from real problems related to the type of using paper and pen) is still used in these technological environments. The current e-Exam systems that have been used in modern education environment are still suffering from many problems, but in spite they solved some traditional exam problems, the authors highlighted these issues and developed a new e-Exam platform to provide a better quality exam in terms of saving cost, time, effort and cheating probability.

The developed e-Exam was implemented upon client/server network architecture on three computer laboratories at the department of IT in LFU. This e-Exam is being used by 14 lecturers to make daily quizzes, midterm and final exams for 142 morning and evening students to replace most of the paper based examinations since October 2015. The developed e-Exam platform includes three main subsystems which are integrated and working together to generate e-Exam Packages and to deliver the e-Examinations. A special e-Exam Browser was implemented using $C$ Sharp to establish the client/server model.

A usability test of e-Exam platform and questionnaires for both lecturers and students were carried out to assess satisfaction and effectiveness. Finally, the empirical outcomes were achieved and mentioned in this paper.

To the best of our knowledge based to review literature and our e-Exam adoption survey, the implemented platform represents the first official e-Exam platform in Kurdistan Region of Iraq.
\end{abstract}

Index Terms-E-Exam, Computer based Test (CBT), Computer based Exam (CBE), QuizMaker, e-Exam Package.

\section{INTRODUCTION}

Young people today live in a world characterized by enforcing the information and communication technology and the modern media culture in our daily life, the use of information and communication technologies is skyrocketing [1].

Although they are witnessing benefits of using technology in the life, the education sector is still suffering from a real problem related to the type of traditional paper and pen exams. These Traditional exams are still used in this technological era where electronic computer devices have replaced most of the paper-based test systems (PBT). Researchers highlighted some problems that related to the traditional paper and pen exam which is also called PBT as a following:

The PBT is not being able to provide interaction with test items, to provide real-life environment by using dynamic graphics and sound and enabling immediate score/result report. Educational experts consider those features that are increasingly used to enhance educational assessments [2]. In a PBT it is not likely to record accurate information, such as item response times [3]. The PBT requires printing, storage, and distribution of booklets, in addition to the collection and scanning of answer sheets, these are no longer suitable [2]. Traditional pen and paper exams have a few methods for assessment [3].

Besides that, a gradual shifting of the philosophy of teaching and learning began moving towards using computers and information and communication technologies to introduce effective teaching environment. This teaching environment has special attention to activities that generate awareness, initiative, inquiry, collaboration, and contribution to new knowledge in obvious ways based computers [4].

Nowadays, many universities have integrated technology in teaching to establish effective teaching environment, these universities had been adopted on advanced learning strategies like Blended Learning Strategy, Flip Learning Strategy, Social Media Learning 
Strategy and so on [5]. For examples, there are 400 University in India using Akash strategy learning [6], 42.000 Schools in Turkey using Fatih strategy learning [7], 141.000 laptops were distributed on schools by Australian government [8]; BYOD (Bring Your Own Device) strategy for education has led to an environment where students use their own devices for daily school related tasks in mature market countries of BYOD such as UK, France, and Germany [9]. And most popular tests these days such as TOEFL, ILETS, IC3, ICDL and more all of them are conducted either partially or fully computer based [10].

All of these have generated a new face for education style and added reason to adopt the new style of exams. By using e-Exams many common problems of traditional exam could be solved to provide a better quality exam in terms of saving cost, time and effort. Table 1 below summarizes the issues addressed by conducting e-Exams. And there are some other papers also cited these advantages of e-Exams [11] [12] [13].

Table 1. E-Exam Benefits

\begin{tabular}{|c|l|}
\hline Beneficiaries & \multicolumn{1}{c|}{ Benefits } \\
\hline Students & Less stress, fair grading, punctual timing \\
\hline Teachers & $\begin{array}{l}\text { Question banks, no grading time, responses time } \\
\text { analysis }\end{array}$ \\
\hline $\begin{array}{c}\text { Faculty or } \\
\text { Department }\end{array}$ & $\begin{array}{l}\text { Less papers, and reduce cheating by questions } \\
\text { randomization }\end{array}$ \\
\hline
\end{tabular}

The significant ideas behind this paper are to provide a better quality exam using information and communication technologies within an existing effective teaching environment in terms of saving cost, time, and effort; and to open the door for the research community to perform newer research work on the related e-Exam systems.

And the original scientific contribution is implementing the first e-Exam platform officially used in Kurdistan Region of Iraq which satisfies both lecturers and students in terms of flexible client/server network architecture, easy web-based application, friendly user interface, multiple question types, multimedia, auto marking, rapidly available scores, resume capability, and auto-submit feature.

For that, this paper presented in the following structure. In the next section, the literature review will be presented. The conceptual design of our developed e-Exam platform using the activity diagram and data flow diagram will be followed. This is followed by explaining the details of main subsystems which are integrated and worked together to deliver the e-Examinations. The implemented solution of conducting e-Exam will be followed. This is followed by the usability test, questionnaires and empirical outcomes at the department of IT in LFU. The paper ends with a conclusion and future works section.

\section{LITERATURE REVIEW}

Many universities and colleges are adopting and making a transition to e-exam systems to provide a better quality exam with the effective teaching environment. For examples:

In the UK, at University College London (ucl.ac.uk), the chosen course management system is Moodle and it is also being used for online quizzes and examinations [14]. For conducting e-assessments, the University of Nottingham developed an open source assessment management tool, known as Rogō e-Exam system for this purpose (nottingham.ac.uk/rogo).

At the University of Helsinki in Finland (helsinki.fi), eExams have been conducted in computer classrooms for around ten years, while traditionally exams written with pen on paper are most often used till now [15]. Another university called Turku University of Applied Sciences (tuas.fi), by the end of June 2014, 1526 e-Exams were done by using Soft Tutor e-Exam system. Essentially, the situation is improving, but the number of teachers actively using the e-Exam system in TUAS is still low [3]

Universities in France start adopting e-Exams to replace traditional exams. For example, pharmacy exams at Universite Joseph Fourier (www.ujf-grenoble.fr) have been organized electronically using tablet computers since 2014 [16].

In Australia, the University of Queensland (uq.edu.au) conducted trials of e-Exams. These exams depended on bring-your-own-device (BYOD) and an open source based e-Exam system and applied in six undergraduate courses during a mid-semester exam in 2014 [17].

In Nigeria, there are a few Universities which have started using the e-Exams system for their test/exams and these includes Federal University of Technology Minna (futminna.edu.ng), University of Ilorin (unilorin.edu.ng), Covenant University Ota (covenantuniversity.edu.ng), National Open University of Nigeria (nou.edu.ng) [18].

The VU University Amsterdam in Netherland (www.vu.nl) with 28000 students is also using computerbased exams to test Bachelor students of three departments (Medicine, Life Science, Art) [15]. There is also the Utrecht University (uu.nl) which started to use Remindo digital assessment software in 2015. In February 2015, Pilot programs of e-Exams were conducted at some various faculties such as (Life Sciences; Law, Economics, and Governance; University Medical Center [19].

In Emirates, Hamdan Bin Mohammed Smart University (hbmsu.ac.ae) is a pioneer university in smart learning. The examinations of students in this university might be online or traditional exams depending on the course type.

Regarding Iraq experience in the field of e-Exams, in Kerbala University, the college of science designed and implemented a secure client/server e-Examinations system for colleges of sciences students [20]. The faculty of archaeology and heritage in University of Kufa also adopted e-Examinations for the students of both the two departments, old Iraqi antiquities and Islamic antiquities through the e-learning environment (Moodle system)[21].

Besides that, there are many researchers focused on adopting and transition to e-Exams systems. In their paper Akinsanmi et al. developed a web application for e- 
assessments which runs through a web browser then it depends on the internet, and it has only multiple choices questions [22]. Adebayo and Muhammad proposed an eExam system and deployed it in six of Nigerian's universities, it runs on internet and intranet, and it starts by taking fingerprints as security measure, then the students will get a multiple choice questions which will be corrected directly after students finish the answers and show their results [18]. Magdi el al proposed a web-based exam system with an auto-grading feature for four types of multiple choices, fill-in the blanks, matching, numeric, and essay questions which require grading by a lecturer [12]. Tufekci et al proposed an online exam system called Mobi which works good in mobile and web modules; sometimes there were problems with reading questions because some mobile phones do not have graphic display function besides a difficulty in reviewing answers in mobile rather than the web [23]. However, our implemented e-Exam system has some advantages like many questions types, auto-grading feature, randomization of questions banks to reduce cheating, auto-submit, and power failure resume feature.

\section{DESIGN OF DEVELOPED E-EXAM PLATFORM}

The conceptual design of our implemented e-Exam platform was carried out using the activity diagram and data flow diagram.

\section{A. Activity Diagram}

The activity diagram is a graphical representation of workflows depicting stepwise activities and actions with support for choice, iteration, and concurrency. An activity diagram shows the overall flow of control. Fig. 1 presents the activity diagram for our developed e-Exam platform.

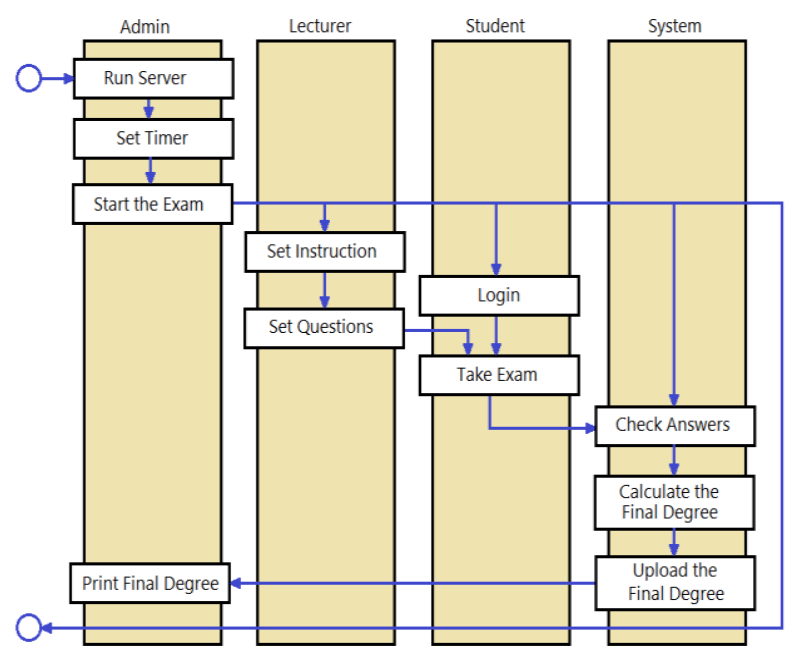

Fig.1. Activity Diagram of e-Exam Platform

\section{B. Data Flow Diagram}

A Data Flow Diagram (DFD) is a graphical representation of functions performed by a system, the data flow among the functions and the relationship between the entities. Fig. 2 presents the data flow diagram for our developed e-Exam platform.

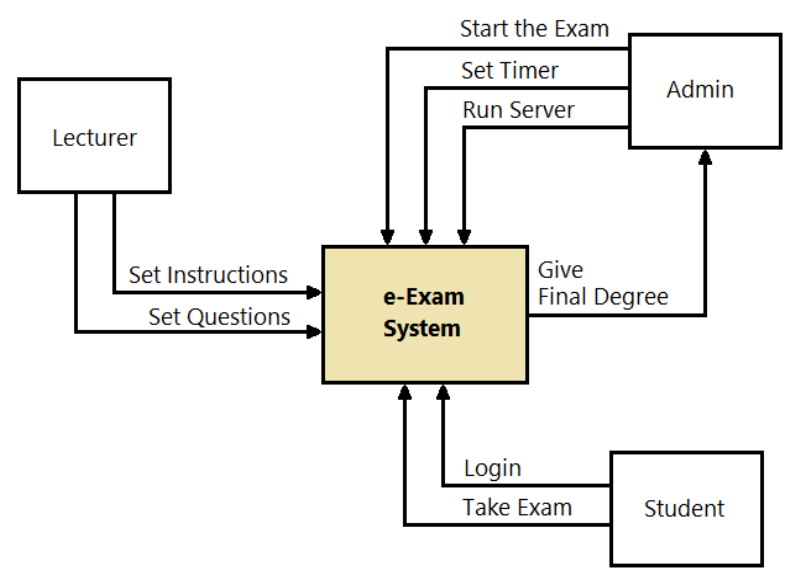

Fig.2. DFD of e-Exam Platform

\section{DEVEloped SubSYSTEMS}

Computer Based Exams is a new approach that has been used nowadays around the world. Basically, the computers are used instead of the papers in the exam. And a special system called e-Exam system is used to browse and answer the questions.

The implemented e-Exam platform includes three main subsystems that are integrated and worked together to deliver the e-Examinations. These subsystems are:

\section{A. The Offline Subsystems}

QuizMaker: This paper adopts iSpring QuizMaker 7 as a software to create questions database and to generate e-Exam package by a randomized set of questions from this questions database. Lecturers (Examiners) who will use QuizMaker offline to create questions database rather than question sheet, set exam's time and special instructions, then upload it to e-Exam Server online. QuizMaker has many important features such as the availability of several types of questions and it can export the exam in HTML 5 format. The selection of iSpring QuizMaker is based on these vital features:

- Easy quiz creation and publishing: its interface is easy to be used and learned by lecturers and other staff. After creating the exam, there three possible options; the first is to publish into single Flash (.SWF) file output, second is to publish into HTML 5 file. In addition, publishing quiz can be made as a combined Flash + HTML5 output. As a result of the easy creation and publishing of e-Exams, the lecturers become motivated and attracted to use this software.

- Settings and Delivery: quiz time limit, the number of attempts for a quiz, receive quiz result by email or server, and printing results. All these features give flexibility for lecturers and administrators of the e-Exam by choosing how they want to collect results, and limitations of the e-Exam to become valid. 
- Quiz design and control: it has 11 graded question and ability to create question groups with shuffled questions and answers. Add different images, videos and equations to the question slide. The variety of questions made lecturers and students more satisfied with the e-Exam usability and credibility. Shuffled questions and answers play an important role in decrease cheating. While using various forms of media aims to make students more engaged with the e-Exam.

- Flexible scoring: the lecturers can grade quiz takers by choosing the suitable scoring system details such as set question marks, partial answer options, and determine passing score. It is also possible to apply same scoring rules for the entire test or treat each question individually in order to set the question difficulty. This type of flexible scoring enables lecturers to conduct fair and accurate e-Exams according to their course, department, and university requirements.

\section{B. The Server Side Subsystem}

Apache Server: The apache software is the core of client/server model, it serves the e-Exam by hosting, running and managing the e-Exam package.

\section{The Client Side Subsystem}

This paper works with two Client Side Subsystem, there are:

- E-Exam Package: The e-Exam with an HTML5 format that generated by QuizMaker will be an 'eExam Package', it is easy to be displayed in the clients' computers through a special e-Exam browser that was developed for this purpose.

- E-Exam Browser: It's a special browser implemented using $\mathrm{C \#}$ to connect the Apache server and establish the client/server model. And to access and browse the e-Exam package in a window without the three buttons of minimizing, maximize, and close. Removing these three buttons aims to decrease the case of closing the exam window accidentally by students. Additionally, three icons of the special browser for the three stages have been inserted as shortcuts on all client computers' desktops to facilitate the access to exam process for the students.

Fig. 3 below show the interface of the browser, the icons of accessing to e-Exams, sample questions, and screen of sending e-exams' results to the server.

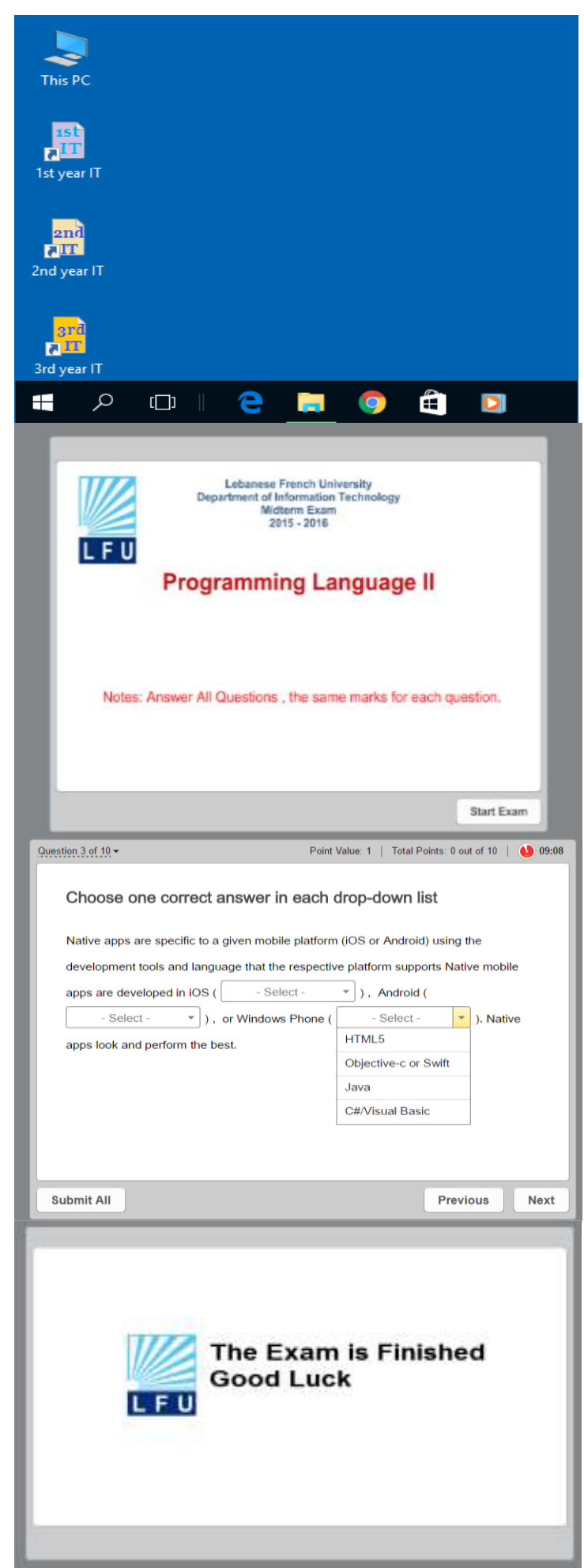

Fig.3. Desktop, the Special Browser Interface, Sample e-Exam Question, and Sending Results to Server Window.

\section{THE IMPLEMENTED E-EXAM PLATFORM}

The main purpose of the implemented e-Exam platform is to provide a new solution to enhance the university academic paper based examinations by adopting an electronic application that has different types of questions. 
To achieve this mission, the implemented platform has been designed and implemented by client/server network architecture and depends on some software technologies to be functional and reliable with its five integrated subsystems.

The following subsection presents 'the general diagram of implemented e-Exam environment and 'the subsystems and their main functions'.

\section{A. Implemented E-Exam Environment}

The general diagram of implemented e-Exam environment shown in Fig. 4.

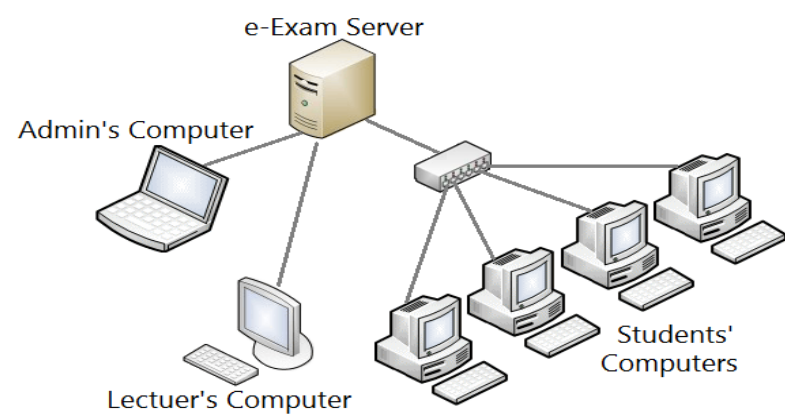

Fig.4. General Diagram of Implemented e-Exam Environment

The e-Exam environment was implemented upon client/server network architecture, and depended on three main work-sides as following:

1) Students side: Includes the students who are using the implemented e-Exam software on their computers rather than papers, to achieve their examinations. They have access to their computers only, each student just to his computer, and they haven't access to any other part.

2) Lecturer(Examiner) side: Includes the person (lecturer in default) who create questions database on his computer offline rather than question sheet, set exam's time and special instructions (if there), then upload it to e-Exam Server online. He has limited access to e-Exam server and no access to computers of students.

3) Admin side: Includes the person (technical staff in default) who manage the network and Subsystems' of e-Exam. He has full access to e-Exam server and computers of students. The lecturer can play both role Examiner and Admin. Also, Admin side includes the e-Exam server that works based on Apache Server and MySQL Database.

The implemented network includes one server (e-Exam Server), one Switch, 60 clients (Computers of Students). All of them are connected with Star LAN network topology and working based on client/server model.

\section{B. Implemented E-Exam Subsystems}

The implemented e-Exam platform has many integrated subsystems, work all together to be a functional and reliable platform. The subsystems of eExam and their main functions are listed in Table 2.

Table 2. The subsystems of e-Exam and their Main Functions

\begin{tabular}{|c|c|c|c|c|}
\hline Subsystem \# & Subsystem Name & Functions & Work Mode & Place \\
\hline 1 & $\begin{array}{l}\text { Quiz } \\
\text { Maker }\end{array}$ & $\begin{array}{l}\text { - Create questions database. } \\
\text { - Generate e-Exam package by randomize set of questions } \\
\text { (from questions database), set exam's time and set special } \\
\text { instructions (if there). }\end{array}$ & Offline & $\begin{array}{l}\text { Lecturer's } \\
\text { Computer }\end{array}$ \\
\hline 2 & Apache Server & $\begin{array}{l}\text { - Serve the e-Exam by hosting, running and managing the e- } \\
\text { Exam package. }\end{array}$ & Online & Server \\
\hline 3 & e-Exam Package & $\begin{array}{l}\text { - Deliver the questions for Students at Clients. } \\
\text { - Tracking the answers, and calculates the Final Degree. }\end{array}$ & Online & Clients \\
\hline 4 & e-Exam Browser & $\begin{array}{l}\text { - Access and browse e-Exam for Students at their Clients. } \\
\text { - Upload the Final Degree of exams to the Server. }\end{array}$ & Online & Clients \\
\hline
\end{tabular}

First of all, lectures (examiners) had finished the generated e-Exam package by a randomized set of questions (from questions database), after that they will upload the e-Exam packages to Apache host server. When Admin activates the exam at the specified date and time, Apache Server allows for clients to access the eExam Package that includes questions of exam via eExam Browser. The e-Exam Browser allows for students to access and browse the e-Exam, and allows to upload the Final Degree of exams to the Server when the time of exam is finished. Fig. 2 shown the data flow diagram of this e-Exam model.

\section{ThE UsABILITY TeST, QUESTIONNAIRES, AND EMPIRICAL OUTCOMES}

To ensure the effectiveness of the e-Exam conducted by IT department, authors implemented these four validation methods:

\section{A. The Usability Test}

This e-Exam platform has been tested and set up by IT department then used in three computer laboratories in the Lebanese French University. 
At the beginning the system was used by a few lecturers to make daily quizzes and after it proved its reliability, the IT department decided to engage this eExam platform in the midterm and final exams to replace most of the paper based examinations.

A total of 158 participants (142 morning and evening students, 14 teachers and 2 administrators) were chosen to administer the usability test of the platform developed. And a total of 28 subjects were chosen to deliver with the implemented e-Exam platform. All students in department of IT made their final exams for semester one and two for academic year 2015-2016 by using implemented e-Exam platform.

The users' behaviors while carrying out these tasks were also observed. While the thought of the radical change of exam's style may intimidate those who are unfamiliar with this style of exam, e-Exams require only minimal computer knowledge, and the staff of IT department has held many seminars for students to get acquainted with how to move the mouse, answer questions and navigate through the e-Exam.

\section{B. Questionnaires}

Researchers designed structured - close ended questionnaire were distributed to all students, teachers and administrators who participated in performing eExaminations.

The questionnaire consisted of 'Likert' and 'Dichotomous' questions and 20 scaled items concerning the examinees' acceptance of the implemented e-Exam platform, and its usability. A scale from 1 (total disagreement - 'Dissatisfied') to 3 (total agreement 'Satisfied') was used.

The major aim of this questionnaire work is to determine the acceptability or otherwise of the existing Paper based Exams (PBE) and the implemented e-Exam platform of examining students in Department of IT in Lebanese French University. The result of the questionnaire was analyzed in Table 3.

Table 3. The Result of the Questionnaire

\begin{tabular}{|c|c|c|c|c|c|c|}
\hline \multirow{2}{*}{ Scale } & \multicolumn{3}{|c|}{ Students } & \multicolumn{3}{c|}{ Examiner } \\
\cline { 2 - 7 } Round & Satisfied & Fair & $\begin{array}{c}\text { Dissat } \\
\text { isfied }\end{array}$ & $\begin{array}{c}\text { Satisfi } \\
\text { ed }\end{array}$ & Fair & $\begin{array}{c}\text { Dissat } \\
\text { isfied }\end{array}$ \\
\hline $1^{\text {st }}$ Round & $95.1 \%$ & $0 \%$ & $4.9 \%$ & $85.7 \%$ & $0 \%$ & $14.3 \%$ \\
\hline $2^{\text {nd }}$ Round & $98.6 \%$ & $0 \%$ & $1.4 \%$ & $100 \%$ & $0 \%$ & $0 \%$ \\
\hline
\end{tabular}

From the analysis of the results in Table 3, it was discovered that out of 142 students who were presented in e-Examinations, 135 students are satisfied, 7 students are dissatisfied and no one was indifferent in the 1st Round Questionnaire. While with the 2nd Round Questionnaire, 140 students are satisfied, 2 students are dissatisfied and no one was indifferent.

Also, out of 14 full-time and part-time lecturers (Examiners) that were attested across the department of IT participated in the questionnaire, 12 lecturers are satisfied, 2 lecturers are dissatisfied (they were not excited and said the e-Exam is not Suitable for their subjects), and no one were indifferent in the 1 st Round
Questionnaire. While with the 2nd Round Questionnaire, 14 lecturers are satisfied.

The deduction from Table 3 was that the majority of the students and lecturers (Examiners) prefer eExamination instead of the traditional paper method for examining students.

\section{The Empirical Outcomes}

The problems that are encountered with the traditional methods concerning the cost, time, efforts and cheating probability are noticed during the implementation of the e-Exam and solved as the following:

1) The e-Exam use less number of papers, which will reduce the cost of the examination and would preserve the environmental conditions.

2) The number of people is required to supervise each examination will be fewer, which will reduce the effort and cost for examination.

3) Timing spent on correcting the papers and reviewing the answers will be eliminated, which will reduce the effort of lecturers.

4) The e-Exam have the ability to produce random questions to each student, which will minimize the cheating probability to almost zero.

5) The e-Exam have the ability to protect from an impersonation fraud during the examination.

\section{D. 'E-Exams Adoption At Universities' Survey}

To ensure that our implemented platform is the first eExam platform officially used in Kurdistan Region of Iraq universities, authors designed a short survey using surveymonkey.com as following:

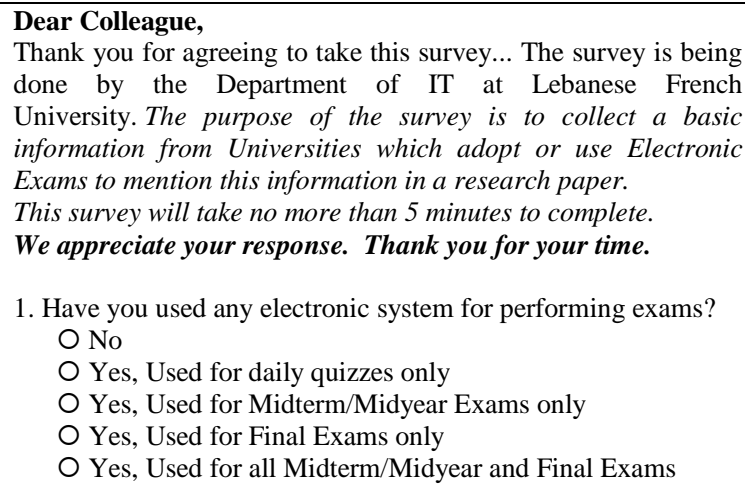

1. Have you used any electronic system for performing exams? O No

Yes, Used for daily quizzes only

Yes, Used for Midterm/Midyear Exams only

Yes, Used for Final Exams only

Yes, Used for all Midterm/Midyear and Final Exams

2. What is the name of the e-Exam system of your University (If there)?

3. The level of implementation of e-Exams at your University (If there)?

At all colleges and departments in my University

At specific departments in my University,

Please list them below (if implement at a specific departments):

4. Name of your University 
The survey covered all public and private universities in Kurdistan Region, which listed by Ministry of Higher Education and Research on its website [24].

\section{CONCLUSION}

The following are some points derived from the implemented platform and empirical works:

1) It is imperative to note that there is no 'plug and play' e-Exam system, whereas the features of any e-Exam system should be reconfigured to be consistent with rules and regulations of a local academic system of a country.

2) As a matter of fact, there is no such an e-Exam system that fits with all educational courses, the key issue for making a successful e-Exam is the nature of course besides willingness of the teacher to take advantages e-Exam. The awareness campaigns are very important to encourage and enthuse students to exploit e-Exams.

3) Besides the ability of the e-Exam system to solve many familiar problems of traditional exams and to provide a better quality exam in terms of saving cost, time, efforts and reduce the cheating probability. The e-Exam system offers many advantages to all academic institutes and universities, academics and students like the following:

a) For academic institutes and universities; e-Exam system offers many advantages, like reducing the cost of an examination by using less number of papers and would preserve the environmental conditions. One more advantage is reducing the cost and effort of exam supervisors by using less number of people.

b) For academics who are interested in applying $e$ Quizzes and e-Exams; e-Exam system offers many advantages, like saving their marking time by automatic evaluation, using question banks that can be used for future exams. One more benefit is to decrease cheating probability via questions randomization. Last but not least, using of multimedia to make the exam more interactive.

c) Students: they can also get benefits out of eExams where results are available rapidly and no disturbing changes in exams during the course.

4) Using an implemented special browser to access and browse the e-exam package is a good way to provide a familiar environment for students which rely upon client/server network architecture.

5) The implemented e-Exam platform represents the first e-Exam platform used officially in Kurdistan Region of Iraq universities.

\section{ACKNOWLEDGMENT}

Authors are thankful to our colleagues (Lectures and
Technical Staff) in Department of IT for providing the required infrastructure and their support.

\section{REFERENCES}

[1] "World Youth Report," [New York]: United Nations Dept of Economic and Social Affairs2005.

[2] F. Scheuermann and J. Björnsson, "The transition to computer-based assessment: New approaches to skills assessment and implications for large-scale testing," Joint Research Centre, Italy, 2009.

[3] M. Kuikka, M. Kitola, and M.-J. Laakso, "Challenges when introducing electronic exam," Research in Learning Technology, vol. 22, 2014.

[4] D. M. S. Al-Hakeem and D. A. a. H. Al-Hamami, "Implementation of Common Secure Framework for IoT based Arduino Platform," International Journal of Computer Trends and Technology (IJCTT), vol. 32, no. 1, pp. 49-53, February 2016.

[5] J. F. Strayer, "How learning in an inverted classroom influences cooperation, innovation and task orientation," Learning Environments Research, vol. 15, no. 2, pp. 171193, 2012.

[6] A. Singha and R. K. Das, "Akash Tablet: A Scope for Virtual Service in College Libraries," 2012.

[7] F. Kalelioğlu and S. Akbaba-Altun, "Middle school students' perceptions and expectations about tablet PCs in TURKEY," International Journal of Multidisciplinary Thought, vol. 4, no. 2, pp. 301-307, 2014.

[8] R. Jamieson-Proctor, P. Redmond, J. Zagami, P. Albion, and P. Twining, "Redefining education for the digital age: a snapshot of the state of play in three Queensland schools," in ACEC 2014 conference proceedings, 2014, vol. 1, pp. 294-301: Australian Council for Computers in Education.

[9] A. French, C. Guo, M. Schmidt, and J. Shim, "An Exploratory Study on BYOD in Class: Opportunities and Concerns," 2015.

[10] R. Giustolisi, G. Lenzini, and G. Bella, "What security for electronic exams?," in 2013 International Conference on Risks and Security of Internet and Systems (CRiSIS), 2013, pp. 1-5: IEEE.

[11] T. M. Fagbola, A. A. Adigun, and A. O. Oke, "Computerbased test (CBT) system for university academic enterprise examination," International journal of scientific \& technology research, vol. 2, no. 8, pp. 336-342, 2013.

[12] M. Z. Rashad, M. S. Kandil, A. E. Hassan, and M. A. Zaher, "An Arabic web-based exam management system," International Journal of Electrical \& Computer Sciences IJECS-IJENS, vol. 10, no. 01, pp. 48-55, 2010.

[13] R. JImoh, M. Yussuff, M. Akanmu, A. Enikuomehin, and I. Salman, "Acceptability of Computer Based Testing (CBT) Mode for Undergraduate Courses in Computer Science," Journal of Science, Technology, Mathematics and Education (JOSTMED), vol. 7, pp. 11-20, 2011.

[14] E. Sorensen, "Implementation and student perceptions of e-assessment in a Chemical Engineering module," European Journal of Engineering Education, vol. 38, no. 2, pp. 172-185, 2013.

[15] A. Rytkönen and L. Myyry, "Student experiences on taking electronic exams at the University of Helsinki," in Proceedings of World Conference on Educational Multimedia, Hypermedia and Telecommunications 2014, 2014.

[16] A. Kassem, Y. Falcone, and P. Lafourcade, "Monitoring electronic exams," in Runtime Verification, 2015, pp. 118135: Springer. 
[17] M. Hillier, "e-Exams with student owned devices: Student voices," in International Mobile Learning Festival Conference, 2015, pp. 582-608.

[18] O. Adebayo and S. M. Abdulhamid, "E-Exams System for Nigerian Universities with Emphasis on Security and Result Integrity," arXiv preprint arXiv:1402.0921, 2014.

[19] U. University. (2016, 4-June ). Educate-it at Utrecht University Available: https://educateit.sites.uu.nl/en/innovate-your-teaching-practice/eassessment/

[20] A. F. M. ALI, "DESIGN AND IMPLEMENTATION OF A SECURE CLIENT/SERVER E-EXAMINATIONS AND EVALUATION SYSTEM FOR COLLEGES OF SCIENCES STUDENTS," presented at the The 4th International Scientific Conference eLearning and Software for Education, Bucharest 14-17 April 2008.

[21] U. o. Kufa. (2016, 1-June). Our College Students Continue to e-exams. Available: http://www.arch.uokufa.edu.iq/en/index.php/tempo-3/384our-college-students-continue-to-e-exams

[22] O. Akinsanmi, O. Ruth, and M. Soroyewun, "Development of an E-Assessment Platform for Nigerian Universities," Research Journal of Applied Sciences, Engineering and Technology, vol. 2, no. 2, pp. 170-175, 2010.

[23] A. Tufekci, H. Ekinci, and U. Kose, "Development of an internet-based exam system for mobile environments and evaluation of its usability," Mevlana Int. J. of Education, vol. 3, no. 4, pp. 57-74, 2013.

[24] (10 Sept). Universities in Kurdistan. Available: http://www.mhe-krg.org/node/23

\section{Authors' Profiles}

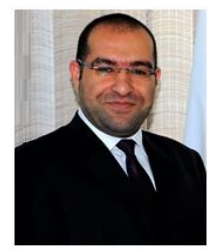

Mazin S. Al-Hakeem (Assistant Professor) received his $\mathrm{PhD}$ degree in Computer Science from University of Technology in 2007 (Iraq). He is currently a Head of IT Department in Lebanese French University (Kurdistan Region of Iraq). He is editorial and reviewer in many national and international journals. Published a four scientific books and several researches in many international conferences and scientific journals. His research interests include network technology, network security, web technology and IoT.

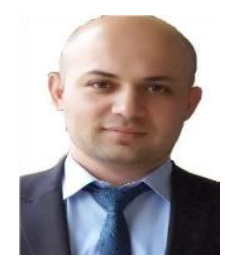

Mohammad Salim Abdulrahman (Assistant Lecturer) received his MSc degrees in Information Technology from the Universiti Tenaga Nasional in 2012 (Malaysia). Currently, he is a full-time lecturer at the Department of Information Technology, Lebanese French University (Kurdistan Region of Iraq). His research interests include cloud computing, information systems and IT governance.

How to cite this paper: Mazin S. Al-Hakeem, Mohammad Salim Abdulrahman,"Developing a New e-Exam Platform to Enhance the University Academic Examinations: the Case of Lebanese French University", International Journal of Modern Education and Computer Science(IJMECS), Vol.9, No.5, pp. 9-16, 2017.DOI: 10.5815/ijmecs.2017.05.02 